\title{
Removal of Pesticide (Endosulphan) from Water via Adsorption onto Activated Carbons Developed from Date Pits
}

\author{
Sheikha. S. Ashour^ \\ Chemistry Department, Applied Science College, Umm El-Qura University, Makkah, PO Box 1847, Kingdom of Saudi Arabia \\ ‘e-mail: sheikha_s_ashour@hotmail.com \\ (Received April 10, 2007; Accepted June 15, 2007)
}

\begin{abstract}
Activated carbons were prepared by impregnation of crushed clean date pits in concentrated solutions of phosphoric acid or zinc chloride followed by carbonization in absence of air at $600^{\circ} \mathrm{C}$. Steam-activated carbon was prepared by gasifying $600^{\circ} \mathrm{C}-$ carbonization product at $950^{\circ} \mathrm{C}$ to a burn-off $=50 \%$. KOH- activated carbon was prepared by impregnating date pitscarbonization product obtained at $450^{\circ} \mathrm{C}$ in concentrated $\mathrm{KOH}$ solution followed by carbonization at $840^{\circ} \mathrm{C}$. Textural properties of these carbons were determined from nitrogen adsorption at $-196^{\circ} \mathrm{C}$ and the chemistry of the carbon surface was investigated by determination and of the surface carbon-oxygen $(\mathrm{C}-\mathrm{O})$ groups using bases of variable strength and dilute $\mathrm{HCl}$. The adsorption of endosulphan at $27^{\circ} \mathrm{C}$ on all the carbons prepared was undertaken. Adsorption of this pesticide at 32 and $37^{\circ} \mathrm{C}$ was also undertaken for steam-activated and $\mathrm{KOH}$-activated carbons. Phosphoric acid-activated carbons and steamactivated carbons are mainly microporous and have high surface concentration of C-O groups of acidic nature. Steamactivated and $\mathrm{KOH}$-activated carbons exhibited surface areas $>1000 \mathrm{~m}^{2} / \mathrm{g}$ and contain micro and non-micrpores. The adsorption of endosulphan was related to the surface area of non-micropores and was retarded by the high concentration of surface C-O groups. The thermodynamic properties indicated the feasibility of the adsorption process and the possible regeneration of the carbon for further use.
\end{abstract}

\section{Introduction}

To achieve higher yields with good quality from newly introduced high-yielding varieties of crops, the use of pesticides is imminent for controlling insects, pests and diseases. Despite their importance in improving and stabilizing agricultural production, these agents are also known to pollute air, water and soil, and thereby produce undesirable effects upon the man and the environment. It becomes necessary to detect, separate, identify and determine pesticide residues in the ecosystem and then take the proper steps for their removal. The adsorption of pesticides on soils has been of considerable significance. The frequent detection of pesticides in surface and ground water has greatly increased experimental studies on pesticide adsorption by soils $[1,2]$. However, the adsorption of pesticide by activated carbons received very little concern. This stimulated the author to devote his interest towards pesticide adsorption from water using activated carbons. Because the price of activated carbons continuously increases, preparation of activated carbons from agricultural wastes is our new trend.

Most of the data on pesticide adsorption by soils deals with aqueous solutions [3-6]. However, a number of investigations have been carried out on the adsorption of pesticides on soils from non-aqueous solvents and solvent mixtures [610] and it was reported that the adsorption capacity for pesticides decreased with the increase of the volume fraction of the organic solvent [11]. On the other hand, the adsorption of pesticides from water may be suppressed by the hydrophilic nature of soil which increased the adsorption of water rather than of the pesticide [12]. Thus, adsorption of pesticides from water is expected to be considerably higher when undertaken by hydrophobic sorbents such as active carbons (ACs). Despite the high cost of these sorbents, the removal of pesticides particularly from drinking water still deserves.

ACs are characterized by their extended surface areas, large total pore volume and wide range of pore size distribution [13] and consequently very high adsorption capacity organic and inorganic pollutants from gas streams as well as from solution [14]. ACs can be prepared from any carbonaceous material and the cost of their production significantly comes down when agricultural wastes are used as precursors for their production [15].

In the present investigation, chemically-activated carbons were prepared from date pits using zinc chloride or phosphoric acid as activating agents, $\mathrm{KOH}$-activated carbon was also prepared using $\mathrm{KOH}$ as activating agent followed by gasification with steam to a burn-off $=25 \%$. Physicallyactivated carbon was also obtained by gasifying date pits carbonization product with steam at $950^{\circ} \mathrm{C}$ to a burn off $=50 \%$. The adsorption of endosulphan from aqueous solutions onto these carbons was at $27^{\circ} \mathrm{C}$ was undertaken. Adsorption of this pesticide at 32 and $37^{\circ} \mathrm{C}$ was also investigated on two selected carbons to determine the thermo- 
dynamic parameters of this adsorption system. Trials have been made to relate the adsorption capacities of endosulphan to any of the surface properties of carbons.

\section{Experimental}

\subsection{Materials}

A large stock of dry, clean and crushed date pits (D) was prepared. Two zinc chloride-activated samples (CZ5) and (CZ10) were obtained by impregnating portions from (D) for $72 \mathrm{~h}$ into saturated zinc chloride solutions containing 50 and 100 wt \% of zinc chloride, respectively. The impregnated samples were heated in absence of air at $600^{\circ} \mathrm{C}$. The carbonized mass was lixiviated with $5 \% \mathrm{HCl}$ and then washed with distilled water till the supernatant was chloride ion-free The active carbon thus obtained was dried and stored in Quick-fit glass container. More details are reported elsewhere [16]. Phosphoric acid-activated carbons (CP4) and (CP6) were prepared by impregnating portions from (D) for $72 \mathrm{~h}$ into concentrated $\mathrm{H}_{3} \mathrm{PO}_{4}$ solutions containing 40 and 60 wt $\%$ of phosphoric acid, respectively. The impregnated solids were dried at $110^{\circ} \mathrm{C}$ before carbonization at $600^{\circ} \mathrm{C}$, in absence of air. The carbonized mass was washed till the $\mathrm{pH}$ of the supernatant was 6.5 and then dried and stored. Details of activation with phosphoric acid are given elsewhere [17]. Steam-activated carbon (CS) was obtained by gasifying $600^{\circ} \mathrm{C}$-carbonization product of (D) with steam at $950^{\circ} \mathrm{C}$ to a burn-off $=50 \%$. Details on steam activation have been previously reported [18]. $\mathrm{KOH}$-activation was carried out using $450^{\circ} \mathrm{C}$-carbonized date pits. This product was crushed and sieved to a uniform size range $0.5-1.0 \mathrm{~mm}$. Equal weights of the carbonization product, water and $\mathrm{KOH}$ were mixed in a stainless steel container, After being dried at $110^{\circ} \mathrm{C}$ for $24 \mathrm{~h}$, the dried product was place in a sealed ceramic oven and heated at a rate of $10^{\circ} \mathrm{C} / \mathrm{min}$ to $780^{\circ} \mathrm{C}$, in nitrogen atmosphere for $1 \mathrm{~h}$. The activation product was cool to room temperature and washed with redistilled. The sample was then poured to a beaker containing $250 \mathrm{ml}$ of $0.1 \mathrm{M} \mathrm{HCl}$ and stirred for $1 \mathrm{~h}$. Finally the sample was washed with distilled water until $\mathrm{pH}$ of the wash solution was about 6-7. The $\mathrm{KOH}$-activated sample was designated (CK). Details on $\mathrm{KOH}$-activation are reported elsewhere [19].

Technical grade endosulphan was a product of Rallis India Ltd., Mumbai and was used without further purification. Its structure can be represented as:

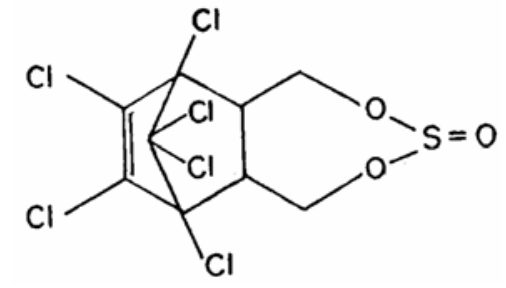

\subsection{Techniques}

The textural properties of the carbons were determined from the adsorption of nitrogen at $-196^{\circ} \mathrm{C}$, using conventional volumetric apparatus. Prior to any adsorption measurement, the carbon sample was degassed at $200^{\circ} \mathrm{C}$ under a reduced pressure of $10^{-5}$ Torr for $8 \mathrm{~h}$.

The $\mathrm{pH}$ of the aqueous solution of the adsorbate and the surface $\mathrm{pH}$ of ACs were determined using digital $\mathrm{pH}$-meter (Pope model No. 1501). The base neutralization capacities (BNC) of the ACs were determined according to the Boehm titration [20]. These were carried out by neutralization of 0 , $1 \mathrm{M} \mathrm{NaHCO} 3, \mathrm{Na}_{2} \mathrm{CO}_{3}, \mathrm{NaOH}$ and $\mathrm{Na}_{2} \mathrm{OC}_{2} \mathrm{H}_{5}$ by carbon samples. Thus $0.25 \mathrm{~g}$ of the carbon sample was mixed wit 50 $\mathrm{ml}$ of the respective solution into $100 \mathrm{ml}$ Quick-fit polyethylene bottles. The suspensions were flushed with nitrogen. Shaking was continued for $24 \mathrm{~h}$. The residual concentration of each solution was determined by titrating the supernatant against $0.1 \mathrm{M} \mathrm{HCl}$. The total amount of surface basicity was determined by neutralization of $0.1 \mathrm{M} \mathrm{HCl}$ by the carbon sample.

The adsorption of endosulphan was performed from aqueous solution by taking different initial concentration of endosulphan. $20 \mathrm{ml}$ of each concentration were transferred to a stoppered glass flask and to each of these solution $0.1 \mathrm{~g}$ of the carbon was added and the suspensions were maintained at $27^{\circ} \mathrm{C}$ in an incubator shaker for $6 \mathrm{~h}$ followed by incubation without shaking for $24 \mathrm{~h}$. The suspensions were centrifuged and the supernatants were collected. The residual concentration of endosulphan was determined spectrophotometrically [21] and the amount adsorbed calculated. Each experiment was made in duplicate and a blank flask containing $0.1 \mathrm{~g}$ of the carbon sample and no endosulphan was used for each set of experiments.Few experiments on endosulphan adsorption at two additional temperatures (32 and $37^{\circ} \mathrm{C}$ ) have been undertaken onto CS and CK carbons.

\section{Results and Discussion}

\subsection{Textural Properties}

The adsorption of nitrogen at $-196^{\circ} \mathrm{C}$ on all the ACs investigated proved to be rapid with the equilibrium attained within 30 min at relative pressures lower than 0.1 and within $20 \mathrm{~min}$ at higher relative pressures. However, $40 \mathrm{~min}$ intervals were allowed between successive adsorption measurements to ensure equilibrium conditions. This may e taken as an evidence that the entire pore structure of the ACs is accessible to nitrogen molecule at $-196^{\circ} \mathrm{C}$ and that the adsorption is not controlled by activated diffusion [22]. The isotherms of $\mathrm{CZ}$ carbons and $\mathrm{CP}$ carbons were of first type according to the BDDT classification [23]. CS and CK carbons exhibited nitrogen adsorption isotherms showing 


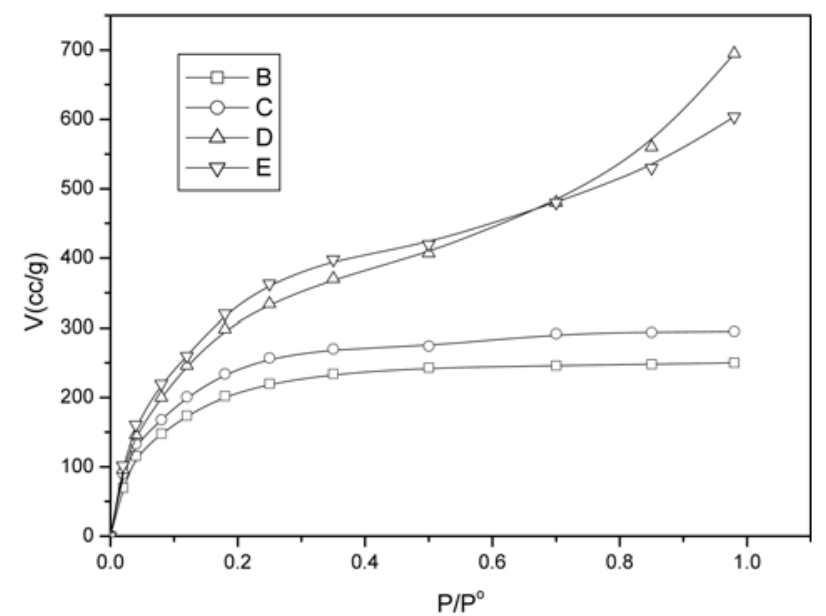

Fig. 1. Representative nitrogen adsorption isotherms at $-196^{\circ} \mathrm{C}$

both the characteristics of type I and type II of the same classification. Representative nitrogen adsorption isotherms are shown in Fig. 1. The conventional BET equation [24] was satisfactorily applied in the relative pressure range 0.05 0.35 . The surface areas $S_{\mathrm{BET}}$ of the ACs were determining adopting the molecular area of nitrogen molecule as 0.162 $\mathrm{nm}^{2}$ [25], the $S_{\text {BET }}$ values $\left(\mathrm{m}^{2} / \mathrm{g}\right)$ are listed in Table 1 . Included also in this Table are the total pore volumes $\mathrm{V}_{\mathrm{T}}$ $(\mathrm{ml} / \mathrm{g})$, as calculated from the volume of nitrogen gas adsorbed at relative pressure very close to saturation, i.e. at $\mathrm{P} / \mathrm{P}$ $=0.98$. The mean pore radius of each carbon was also calculated from the relation:

$$
\mathrm{r}_{\mathrm{m}}(\mathrm{nm})=2 \mathrm{~V}_{\mathrm{T}} \times 10^{3} / \mathrm{S}_{\mathrm{BET}}
$$

The $r_{m}$ values of the ACs are given in Table 1. Another independent method, namely the $\alpha$-method [26] was also used to analyze the nitrogen adsorption isotherms. This method plots the volume of nitrogen adsorbed versus reduced isotherm determined on non-porous carbon. The adsorption data report by Sellez-Perez and Martin-Martinez [27] were used for such plots. Representative $\alpha$ plots are shown in Fig. 2. The extrapolation of the $\alpha$ plot to the origin determines the surface area $S^{\alpha}$ (Table 1). It seems logical to extrapolate, where possible, to the origin of coordinates in the $\alpha$ plots. This extrapolation cannot be done for all the carbons, $\alpha$ plots

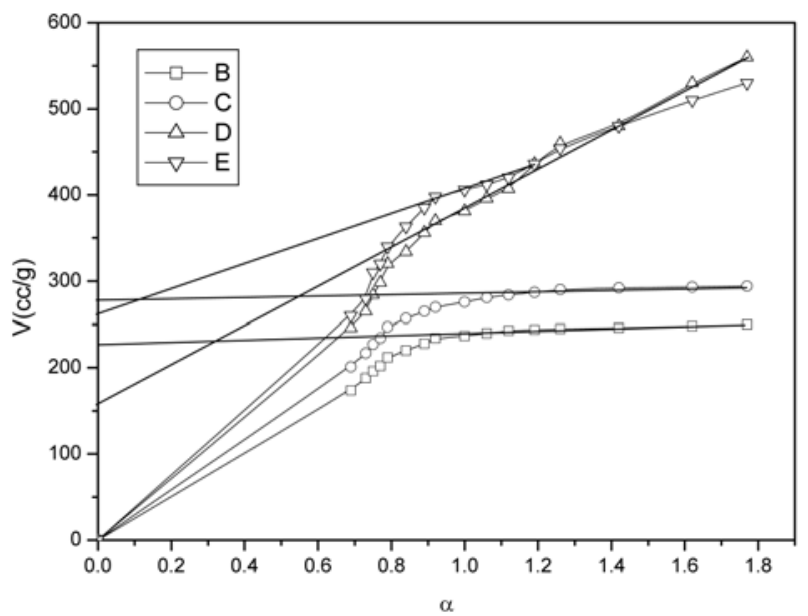

Fig. 2. Representative $\alpha$-plots of nitrogen adsorption at $-196^{\circ} \mathrm{C}$.

can become curved in the lower relative pressure region [27] and extrapolation to the origin is not always possible. This limitation could arise from the standard reference material or from the $\alpha$ method, although this kind of deviation has been ascribed to the presence of narrow microporosity in the activated carbon [27]. In this investigation the reference nonporous carbon was used and therefore the author is inclined to ascribe the deviation to the existence of a large fraction of narrow micropores in the ACs investigated. The very small $r_{m}$ values may be taken as an evidence for this explanation.

The $\alpha$-method allows also the determination of other textural parameters. These are the surfaces located in micropores and in non-micropores, $\mathrm{S}_{\mathrm{m}}^{\alpha}$ and $\mathrm{S}_{\mathrm{n}}^{\alpha}$, respectively. The same method can give also the volumes of micopores and non-micropores $\mathrm{V}^{\alpha}{ }_{\mathrm{m}}$ and $\mathrm{V}^{\alpha}{ }_{\mathrm{n}}$, both expressed in $(\mathrm{ml} / \mathrm{g})$. These textural parameters are also given in Table 1 .

Inspection of Table 1 reveals that: 1- the surface area and total pore volume of $\mathrm{CZ}$ carbons increased with the increase of the percentage of zinc chloride used in activation. The same was also true for $\mathrm{CP}$ carbons, i.e. $\mathrm{S}_{\mathrm{BET}}$ and $\mathrm{V}_{\mathrm{T}}$ increased with the percentage of phosphoric acid used in activation. 2- $\mathrm{S}_{\mathrm{BET}}$ and $\mathrm{S}^{\alpha}$ are more or less comparable which may be taken as an evidence for the correctness of the surface areas calculated. 3- For CZ and CP carbons, $\mathrm{S}^{\alpha}{ }_{\mathrm{m}}$ and $\mathrm{V}^{\alpha}{ }_{\mathrm{m}}$ are by far higher than $\mathrm{S}_{\mathrm{n}}^{\alpha}$ and $\mathrm{V}_{\mathrm{n}}^{\alpha}$. Comparable $\mathrm{S}_{\mathrm{n}}{ }_{\mathrm{n}}$ and

Table 1. Textural properties of the carbons investigated

\begin{tabular}{lcccccccc}
\hline Carbon & $\mathrm{S}_{\mathrm{BET}}\left(\mathrm{m}^{2} / \mathrm{g}\right)$ & $\mathrm{V}_{\mathrm{T}}(\mathrm{ml} / \mathrm{g})$ & $\mathrm{r}_{\mathrm{m}}(\mathrm{nm})$ & $\mathrm{S}^{\alpha}\left(\mathrm{m}^{2} / \mathrm{g}\right)$ & $\mathrm{S}_{\mathrm{n}}^{\alpha}\left(\mathrm{m}^{2} / \mathrm{g}\right)$ & $\mathrm{S}_{\mathrm{m}}^{\alpha}\left(\mathrm{m}^{2} / \mathrm{g}\right)$ & $\mathrm{V}_{\mathrm{m}}^{\alpha}(\mathrm{ml} / \mathrm{g})$ & $\mathrm{V}_{\mathrm{n}}^{\alpha}(\mathrm{ml} / \mathrm{g})$ \\
\hline $\mathrm{CP} 4$ & 904 & 0.390 & 0.97 & 777 & 40 & 737 & 0.336 & 0.064 \\
$\mathrm{CP6}$ & 982 & 0.498 & 1.01 & 938 & 98 & 840 & 0.372 & 0.126 \\
$\mathrm{CZ5}$ & 641 & 0.302 & 0.94 & 648 & 70 & 578 & 0.212 & 0.090 \\
$\mathrm{CZ10}$ & 906 & 0.459 & 1.01 & 875 & 137 & 738 & 0.349 & 0.110 \\
$\mathrm{CS}$ & 1175 & 1.085 & 1.85 & 1156 & 612 & 544 & 0.290 & 0.795 \\
$\mathrm{CK}$ & 1265 & 0.956 & 1.51 & 1226 & 480 & 746 & 0.372 & 0.584 \\
\hline
\end{tabular}


$\mathrm{S}^{\alpha}{ }_{\mathrm{m}}$ have been exhibited by CS, i.e. 612 and $544 \mathrm{~m}^{2} / \mathrm{g}$, respectively. For CK, $S^{\alpha}{ }_{n}$ was lower than $S^{\alpha}{ }_{m}$, i.e. 480 and $716 \mathrm{~m}^{2} / \mathrm{g}$. 4- The mean pore radii of $\mathrm{CZ}$ and $\mathrm{CP}$ carbons are either slightly smaller or slightly larger than $1.0 \mathrm{~nm}$ indicating that these carbons are mainly miroporous. The mean pore radii of $\mathrm{CS}$ and $\mathrm{CK}$ are 1.85 and $1.51 \mathrm{~nm}$, respectively indicating that they contain both micro and mesoporosity.

\subsection{Chemistry of the Carbon Surfaces}

The chemistry of the surface of a carbon is equally important to its textural properties in determining its adsorption capacity, particularly in adsorption from solution. The chemistry of the carbon surface is attributed to the existence on the surface, of carbon-oxygen $\mathrm{C}-\mathrm{O}$ groups of acidic or basic character. The $\mathrm{pH}$ of the aqueous suspension of carbon material (Table 2), provides a convenient indicator of the carbon surface. The $\mathrm{pH}$ values of $\mathrm{CZ5}$ and $\mathrm{CZ10}$ wee measured to be 5.5 and 4.9, respectively, whereas those of CP4 and CP6 were found to be 4.3 and 3.7, respectively. This may be taken as an evidence of the predominance of the acidic functional groups on the surface of these carbons. The surface $\mathrm{pH}$ of CS was found to be 8.9 indicating higher surface concentration of $\mathrm{C}-\mathrm{O}$ groups of basic character. The $\mathrm{pH}$ of $\mathrm{CK}$ was measured to be 6.5, i.e., approximately neutral or that comparable concentrations of basic and acidic groups characterize the surface of this particular carbon. The chemistry of the surfaces of ACs is also determined from their base neutralization capacities (BNC) and the total surface acidity, both expressed in (meq./g). The various acidic functional groups on the carbon surface can be determined using selective neutralization by equilibration with series of bases of increasing strength, i.e. $\mathrm{NaHCO}_{3}, \mathrm{Na}_{2} \mathrm{CO}_{3}, \mathrm{NaOH}$ and $\mathrm{NaOC}_{2} \mathrm{H}_{5}$. $\mathrm{NaHCO}_{3}$ neutralizes carboxylic groups whereas those neutralized by $\mathrm{Na}_{2} \mathrm{CO}_{3}$ but not by $\mathrm{NaHCO}_{3}$ were believed to be lactones. The weakly acidic groups neutralized by $\mathrm{NaOH}$ but not by $\mathrm{Na}_{2} \mathrm{CO}_{3}$ were postulated as phenols. The reaction with $\mathrm{NaOC}_{2} \mathrm{H}_{5}$ but not with $\mathrm{NaOH}$ was not considered as a true neutralization reaction since it did not involve exchange by $\mathrm{H}^{+}$or $\mathrm{Na}^{+}$ions. The groups reacting with $\mathrm{NaOC}_{2} \mathrm{H}_{5}$ but not with $\mathrm{NaOH}$ were suggested to be carbonyls [28]. The basic groups on the surfaces of ACs were determined by neutralization with $0.1 \mathrm{M} \mathrm{HCl}$. The different functional groups on the surface of ACs investigated are listed in Table 2, expressed as (m eq./g). Included also in this table are the surface densities of $\mathrm{C}-\mathrm{O}$ groups $\left(\mathrm{d}_{\mathrm{C}-\mathrm{O}}\right.$ in $\mu$ eq. $\left./ \mathrm{m}^{2}\right)$, which is the total amount of acid and basic functional groups on the surface of one gram carbon divided by $S_{\text {BET }}\left(\mathrm{m}^{2} / \mathrm{g}\right)$ of this carbon.

It is evident from Table 2 that: 1 - Generally, the $\mathrm{pH}$ values of CP carbons are lower than those of $\mathrm{CZ}$ carbons. This is consistent with the surface concentration of the acidic groups of these carbons. An evidence for this consistency is the lower surface basicity of $\mathrm{CP}$ carbons compared with $\mathrm{CZ}$ carbons. 2-The concentration of acidic groups on the surface of CS carbon is considerably lower compared with CP and $\mathrm{CZ}$ carbons, the opposite is the case when the surface concentrations of the basic groups of these carbons were considered. 3- $\mathrm{d}_{\mathrm{C}-\mathrm{O}}$ of $\mathrm{CP} 4$ is the maximum whereas that of $\mathrm{CK}$ is the minimum, $\mathrm{d}_{\mathrm{C}-\mathrm{O}}$ depends both on the amount of $\mathrm{C}$ $\mathrm{O}$ groups as well as on the extent of the surface area. Evidently, $\mathrm{d}_{\mathrm{C}-\mathrm{O}}$ follows the trend : $\mathrm{CP} 4>\mathrm{CP} 6>\mathrm{CZ5}>$ $\mathrm{CZ10}>\mathrm{CS}>\mathrm{CK}$.

\subsection{Adsorption of Endosulphan}

Adsorption of endosulphan was undertaken by al ACs investigated from aqueous solution without buffering. Adsorption isotherms linking the amount of endosulphan adsorbed $(\mathrm{mg} / \mathrm{g})$ on ACs and the amount of endosulphan in equilibrium solution $(\mathrm{mg} / \mathrm{l})$ were plotted and are depicted in Fig. 3. The isotherms are of the Langmuirian type, i.e. of the Ltype according to the classification of Giles [29]. The adsorption isotherms were analyzed by the application of Freundlich equation. The linear form of this equation is:

$$
\log \mathrm{q}_{\mathrm{e}}=\log \mathrm{K}_{\mathrm{F}}+1 / \mathrm{n} \log \mathrm{C}_{\mathrm{e}}
$$

where $\mathrm{q}_{\mathrm{e}}$ is the amount of endosulphan $(\mathrm{mg} / \mathrm{g})$ adsorbed at the equilibrium concentration $\mathrm{C}_{\mathrm{e}}(\mathrm{mg} / \mathrm{l}), \mathrm{K}_{\mathrm{F}}$ is known as Freundlich constant and is related to the adsorption capacity and $1 / \mathrm{n}$ is related to the adsorption intensity. Satisfactory linear relation was found when $\log \mathrm{q}_{\mathrm{e}}$ was plotted versus $\log$ $\mathrm{C}_{\mathrm{e}}$ (Fig. 4), the values of $\mathrm{K}_{\mathrm{F}}$ and $1 / \mathrm{n}$ are listed in Table 3. Fig. 4 depicts fair fitting of endosulphan adsorption to this empirical equation.

The Langmuir equation was also used to analyze the

Table 2. Surface C-O groups (meq./g) and surface density of C-O groups $\mathrm{d}_{\mathrm{C}-\mathrm{O}}$ ( $\mu$ eq./g)

\begin{tabular}{lcccccccc}
\hline Carbon & PH & Carboxyl & Lactonic & Phenolic & Carbonyl & Total acidic & Total basic & $\mathrm{d}_{\text {C-O }}$ \\
\hline CP4 & 4.3 & 0.15 & 0.12 & 0.08 & 0.18 & 0.53 & 0.07 & 0.74 \\
CP6 & 3.7 & 0.20 & 0.15 & 0.08 & 0.21 & 0.64 & 0.06 & 0.70 \\
CZ5 & 5.5 & 0.06 & 0.08 & 0.05 & 0.10 & 0.29 & 0.07 & 0.62 \\
CZ10 & 4.9 & 0.08 & 0.12 & 0.08 & 0.14 & 0.42 & 0.10 & 0.57 \\
CS & 8.9 & 0.04 & 0.04 & 0.05 & 0.06 & 0.19 & 0.26 & 0.38 \\
CK & 6.5 & 0.06 & 0.05 & 0.07 & 0.08 & 0.26 & 0.21 & 0.37 \\
\hline
\end{tabular}




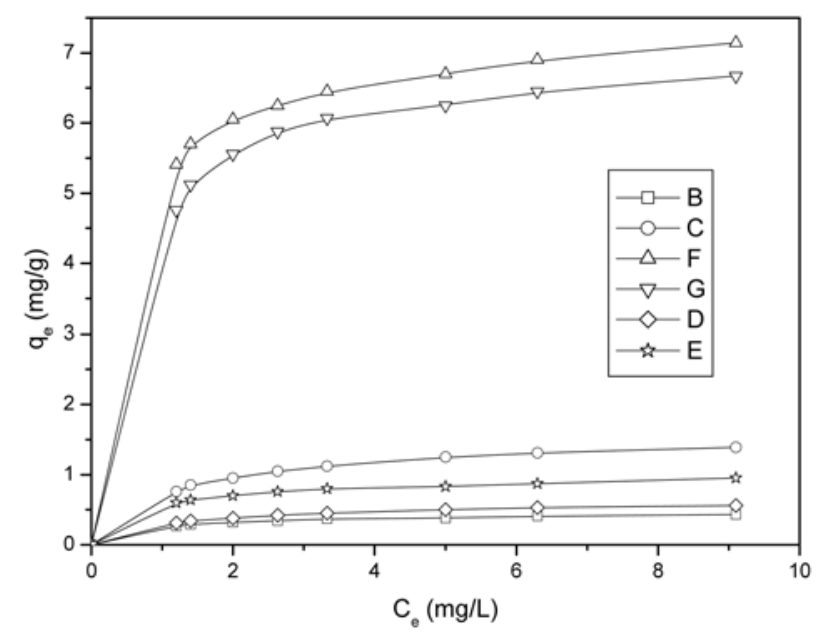

Fig. 3. Adsorption isotherms of endosulphan a $27^{\circ} \mathrm{C}$.

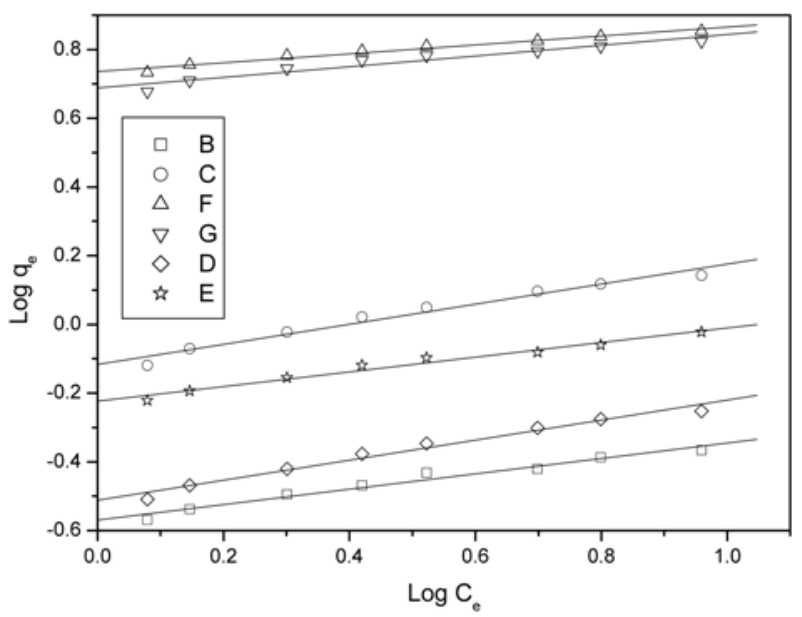

Fig. 4. Linear Freundlich plots of endosulphan adsorption at $27^{\circ} \mathrm{C}$.

endosulphan adsorption isotherms. The linearized Langmuir equation may be written as:

$$
1 / \mathrm{q}_{\mathrm{e}}=\left(1 / \mathrm{q}_{\mathrm{m}} \mathrm{b}\right)\left(1 / \mathrm{C}_{\mathrm{e}}\right)+1 / \mathrm{q}_{\mathrm{m}}
$$

where $\mathrm{q}_{\mathrm{m}}(\mathrm{mg} / \mathrm{g})$ is the maximum adsorption capacity and $\mathrm{b}$ $(1 / \mathrm{mg})$ is related to the energy of adsorption. $\mathrm{q}_{\mathrm{e}}$ and $\mathrm{C}_{\mathrm{e}}$ have been previously identified. Linear Langmuir plots of endosulphan adsorption at $27^{\circ} \mathrm{C}$ are shown in Fig. 4. Evidently, endosulphan adsorption results showed better fitting to the Langmuir equation (Fig. 5), compared with The fitting to Freundlich equation. The isotherms show well developed plateaus and therefore $\mathrm{q}_{\mathrm{m}}$ could also be considered as a measure of the monolayer capacity, $\mathrm{q}_{\mathrm{m}}$ and $\mathrm{b}$ for each adsorption system are listed in Table 3. Included also in Table 3 are the regression coefficients $\left(r^{2}\right)$ obtained from the application of Freundlich and Langmuir models. This indicates once again the better fitting of the present data to Langmuir model.
Table 3. Freundlich and Langmuir constants of endosulphan adsorption at $27^{\circ} \mathrm{C}$

\begin{tabular}{l|cc|cc}
\hline \multirow{2}{*}{ Carbon } & \multicolumn{2}{|c|}{ Freundlich constants } & \multicolumn{2}{c}{ Langmuir constants } \\
\cline { 2 - 5 } & $\mathrm{K}_{\mathrm{F}}$ & $1 / \mathrm{n}$ & $\mathrm{q}_{\mathrm{m}}(\mathrm{mg} / \mathrm{g})$ & $\mathrm{b}(\mathrm{l} / \mathrm{g})$ \\
\hline $\mathrm{CP} 4$ & 0.150 & 050 & 0.46 & 1.22 \\
$\mathrm{CP} 6$ & 0.180 & 0.56 & 1.03 & 1.26 \\
$\mathrm{CZ5}$ & 0.160 & 0.39 & 0.67 & 0.85 \\
$\mathrm{CZ10}$ & 0.186 & 0.57 & 1.83 & 0.58 \\
$\mathrm{CS}$ & 3.980 & 0.33 & 8.30 & 2.167 \\
$\mathrm{CK}$ & 3.100 & 0.33 & 6.90 & 2.216 \\
\hline
\end{tabular}

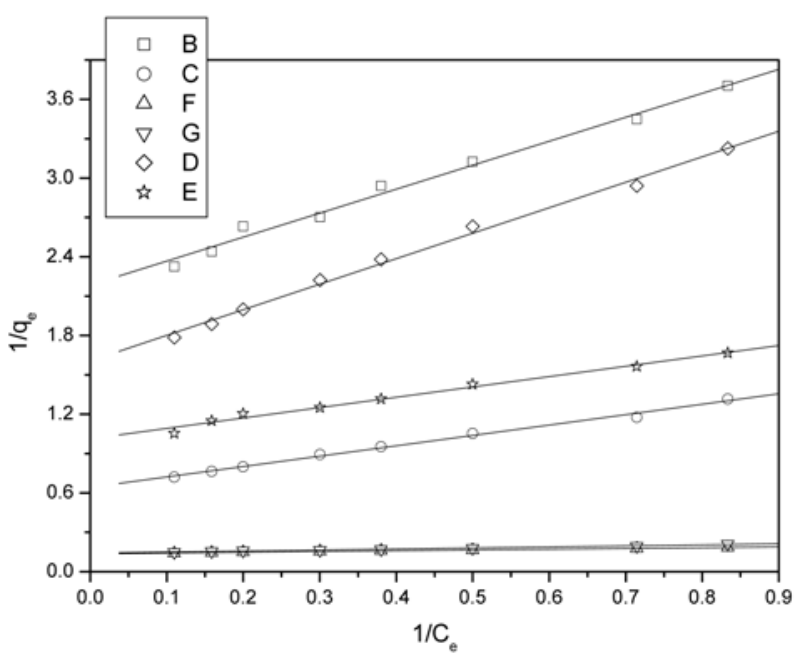

Fig. 5. Linear Langmuir plots of endosulphan adsorption at $27^{\circ} \mathrm{C}$.

It is evident from Table 3 that: 1 - the adsorption capacity of CP carbons for endosulphan increases with the increase of the activating agent $\left(\mathrm{H}_{3} \mathrm{PO}_{4}\right)$ as indicated from the values of $\mathrm{K}_{\mathrm{F}}$ and $\mathrm{q}_{\mathrm{m}}$. The same was also true for $\mathrm{CZ}$ carbons. 2- CS and $\mathrm{CK}$ exhibited high adsorption capacities for endosulphan as compared with $\mathrm{CP}$ and $\mathrm{CZ}$ carbons. This may be attributed to the difference in the pore dimensions of these carbons. Endosulphan is bulky molecules and therefore is expected to be inaccessible to micropores predominating in $\mathrm{CP}$ and $\mathrm{CZ}$ carbons. Moreover, $\mathrm{CP}$ and $\mathrm{CZ}$ carbons are characterized by relatively high surface densities of $\mathrm{C}-\mathrm{O}$ groups. The existence of large concentration of these groups on the surface of microporous carbon probably retards the adsorption in general and of bulky molecules in particular. The adsorption capacities exhibited by CS and CK are satisfactory considering that the adsorption was undertaken from low concentrated solution to simulate the real case. Adsorption from solution increases considerably with the increase of the concentration and most probably the carbons investigated here would show high adsorption capacities from more concentrated solutions.

On the abovementioned basis a trial has been made to 


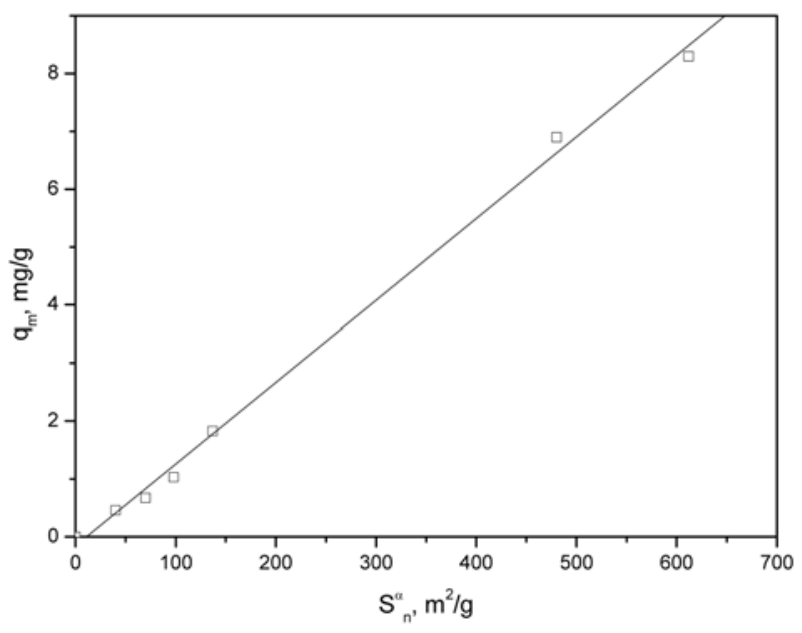

Fig. 6. $q_{m}$ as a function of $S_{n}^{\alpha}$.

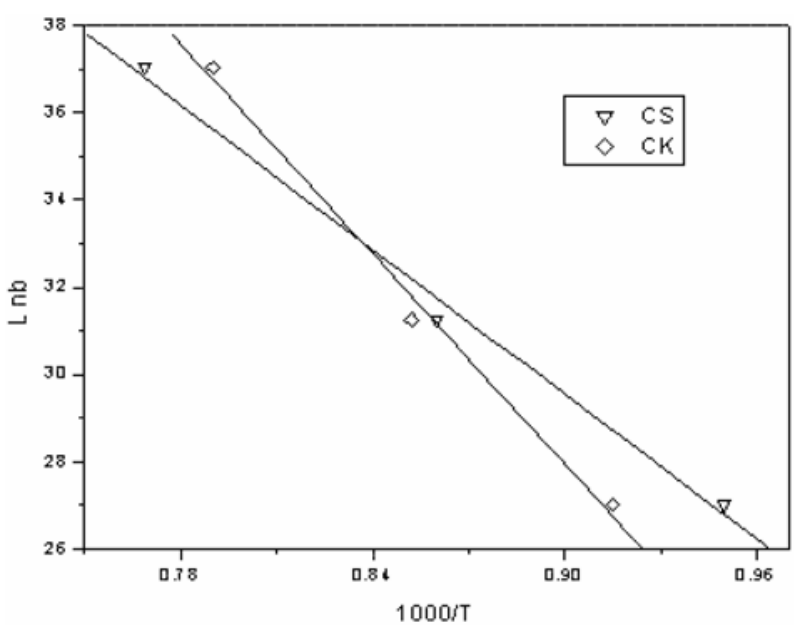

Fig. 7. Ln b versus $1000 / \mathrm{T}\left(\mathrm{K}^{-1}\right)$ of endosulphan adsorption onto $\mathrm{CS}$ and $\mathrm{CK}$.

Table 4. Thermodynamic parameters $(\mathrm{kJ} / \mathrm{mol})$ of endosulphan adsorption by $\mathrm{CS}$ and $\mathrm{Ck}$ at 27,32 and $37^{\circ} \mathrm{C}$

\begin{tabular}{lcccccccccc}
\hline \multirow{2}{*}{ Carbon } & \multicolumn{3}{c}{ at $27^{\circ} \mathrm{C}$} & \multicolumn{3}{c}{ at $32^{\circ} \mathrm{C}$} & \multicolumn{3}{c}{ at $37^{\circ} \mathrm{C}$} \\
\cline { 2 - 11 } & $-\Delta \mathrm{H}$ & $-\Delta \mathrm{G}$ & $-\Delta \mathrm{S}$ & $-\Delta \mathrm{H}$ & $-\Delta \mathrm{G}$ & $-\Delta \mathrm{S}$ & $-\Delta \mathrm{H}$ & $-\Delta \mathrm{G}$ & $-\Delta \mathrm{S}$ \\
\hline $\mathrm{CS}$ & 13.70 & 1.92 & 0.040 & 13.70 & 2.18 & 0.038 & 13.70 & 2.45 & 0.036 \\
$\mathrm{CK}$ & 7.77 & 1.97 & 0.019 & 7.77 & 2.16 & 0.018 & 7.77 & 2.32 & 0.017 \\
\hline
\end{tabular}

related the endosulphan adsorption capacity of the carbon, as expressed by $\mathrm{q}_{\mathrm{m}}$ and the extent of the surface located in nonmicropores $S^{\alpha}{ }_{n}$. Fig. 6 shows such a linear relation which indicates that adsorption of endosulphan is restricted to the mesopores. The fact that the straight line representing this relation passes through the origin may also explain the inaccessibility of micropores to endosulphan molecule.

The adsorption of endosulphan by CS and CK was also undertaken at two additional temperatures, namely 32 and $37^{\circ} \mathrm{C}$. This allowed the determination of the thermodynamic parameters of the present adsorption system using the Langmuir adsorption constant as suggested by Panday et al [30].

$$
\begin{aligned}
& \text { Ln } b=\ln b^{\prime}-\Delta H / R T, \\
& \text { Ln } 1 / b=-\Delta G / R T \\
& \Delta S=(\Delta H-\Delta G) / T
\end{aligned}
$$

The value of $\Delta \mathrm{H}$ is obtained by plotting $\mathrm{Ln} b$ versus $1 / \mathrm{T}$ (Fig. 7). Table 4 lists these adsorption thermodynamic parameters. For CS, qm values of 8.3, 7.6 and $7.0(\mathrm{mg} / \mathrm{g})$ were calculated at 27,32 and $37^{\circ} \mathrm{C}$, respectively, whereas $\mathrm{q}_{\mathrm{m}}$ values of $6.9,6.4$ and $5.9(\mathrm{mg} / \mathrm{g})$ were calculated for $\mathrm{CK}$ at these temperatures, respectively. The negative values of $\Delta \mathrm{H}$ indicate that the adsorption of endosulphan on CS and CK is exothermic and the negative values of $\Delta G$ indicate the spontaneous nature of the adsorption process. The small negative values of $\Delta S$ demonstrate the reversibility of the adsorption process and the possibility of regeneration of the carbon for further adsorption cycles.

\section{Conclusions}

$\mathrm{CP}$ and $\mathrm{CZ}$ carbons exhibited high surface areas with most of the surface located in micropores. The surface $\mathrm{pH}$ of these carbons and the analysis of their surface $\mathrm{C}-\mathrm{O}$ groups indicated their surface acidity. CS and CK carbons have high surface areas and total pore volumes and contain both micro and mesoporosity. The surface densities of $\mathrm{C}-\mathrm{O}$ groups on these carbons are lower compared with those on $\mathrm{CP}$ and $\mathrm{CZ}$ carbons with most of the surface groups of the basic nature. Endosulphan adsorption is determined by the surface located in non-micropores and is retarded by the high concentration of C-O groups, particularly in case of microporous carbon. Steam-activated carbon and $\mathrm{KOH}$-activated carbons exhibited high pesticide uptake although, this uptake was from very low concentrated solution. The thermodynamic adsorption parameters of endosulphan indicate the feasibility of the adsorption process.

\section{References}

[1] Hallberg, G. R. Agric. Ecosyst. Environ. 1989, 26, 299.

[2] Leistra, M.; Boesten, J. J. T. I. Agric. Ecosyst. Environ. 1989, 26, 369. 
[3] Arienzo, M.; Sanchez-Camazano, M.; Cristano-Harrero, T.; Sanchez-Martin, M. J. Chemosphere 1993, 27, 1409.

[4] Singh, R. P.; Kumari, K.; Singh, D. Ecotoxical Environ. Saftey 1994, 28, 5.

[5] Singh, R. P.; Dhirendra, S. Adsorp. Sc. Technol. 1997, 15, 135.

[6] Singh, R. P. Adsortp. Sci. Technol. 1996, 13, 305.

[7] Arienzo, M.; Sanchez-Camazano, M.; Cristano, H. T.; Sanchez-Martin, M. J. Journal Name 1993, 27, 1409.

[8] Rawat, J. P.; Iraqi-Umar, S. M.; Singh, R. P. Adsorp. Sci. Technol. 1997, 15, 649.

[9] Walter, R. W.; Gulseppl-Elle, A. Environ Sci. Technol. 1988, 22, 819.

[10] Ashour, S. Egypt J. Chem. 2007, in Press.

[11] Rawat, J. P.; Iraqi, S. M. U.; Singh, R. P. Adsorp. Sci. Technol. 1997, 15, 649.

[12] El-Geundi, M. S.; Farag, T. E.; Abd El-Ghany, H. M. Adsorp. Sci. Technol. 1998, 23, 437.

[13] Molina-Sabio, M.; Rodriguez-Reinozo, F.; Caturla, F.; Selles, M. J. Carbon 1996, 34, 457.

[14] Patrick, W. E. "Porosity in Carbons", Edward Arnold, London, 1995, 28.

[15] Yong, Z.; Bu-Zing, H. Adsorp. Sci. Technol. 2000, 18, 573.

[16] Youssef, A. M.; Abdel-Bary, E. M.; Samra, S. E.; Dawidar, A. M. J. Appl. Polym. Sci. 1994, 55, 197.
[17] Hourieh, M. A.; Alaya, M. N.; Youssef, A. M.; ElSejarieh, F. Adsorp. Sci. Technol. 1999, 17, 675.

[18] Wu, F. C.; Tseng, R. L.; Jwang, R. S. J. Colloid Interface Sci. 2005, 283, 49.

[19] Youssef, A. M.; El-Nabarawy, Th.; Samra, S. E. Colloids and Surf. 2004, 235, 153.

[20] Boehm, H. P. Advances in Catalysis 1966, 16, 174.

[21] Singh, R. P.; Rawat, J. P.; Kumar, R. Adsorp. Sci. Technol. 2000, 18, 333.

[22] Youssef, A. M.; Ghazy, T. M.; El-Nabarawy, Th. Carbon 1982, 20, 113.

[23] El-Dein, H. A., Ph. D. Thesis, Aleppo Univ., Aleppo, Syria 2007.

[24] McDonald, J. A. F.; Quinn, D. F. G. Porous Mat. 1995, 1, 43.

[25] Wang, S.; Boyjoo, Y.; Choueib, A.; Zu, Z. H. Water Res. 2005, 39, 129.

[26] Rodriguez-Vaero, R. M.; Escandell, M. M.; Molina-Sabio, M.; Rodriguez-Reinoso, F. Carbon 2001, 39, 320.

[27] Sellez-Perez, M. J.; Martin-Martinez, J. M. J. Chem. Soc. Faraday Trans. 1991, 87, 827.

[28] Cox, M.; El-Shafey, E. I.; Pichugin, A. A.; Appleton, C. J. J. Chem. Tech. Biotechnol. 1999, 74, 1019.

[29] Basar, C. A. Hazardous Mat. 2006, 126, 266.

[30] Panday, K. K.; Prasad, G.; Singh, V. N. Water Res. 1985, 19, 869 . 